\title{
Physiotheraphy in Chest Conditions
}

\author{
By MARJORIE MCDOWELL, M.C.S.P. \\ Physiotherapist, Brompton Hospital for Chest Diseases, London, England.
}

\section{Chronic Bronchitis}

Chronic Bronchitis in a lesser or greater degree is prevalent throughout the world and certainly in the United Kingdom it is a crippling and disabling disease and a great deal of research is being done as to its causes, prevention and treatment.

Chronic bronchitis and emphysema account for the loss of more man hours of work than any other disease in Britain -about 25-30 million days a year, and in hospital respiratory diseases account for nearly one quarter of all admissions. In a country such as ours with over employment this is obviously a very serious matter.

Climate naturally plays a great part in respiratory diseases as was dramatically shown by the great fog in London in 1952 which lasted for four days and resulted in an estimated 5,000 deaths. A cold moist atmosphere by itself does not particularly predispose to respiratory affections but if air pollution is added to it bronchitis and pneumonia tend to ensue.

A very important cause of bronchit is is smoking. Tobacco smoke causes bronchial irritation with the result that excessive mucus is formed. In time this will become evident in the form of mucoid sputum.

\section{Treatment}

Prophylaxis is probably the most effective method of treatment available at the present time.

This means whenever possible avoiding infections, inclement weather and exposure, and above all giving up smoking.

Until a few years ago nearly all our bronchitic patients were treated as out patients because there were no beds available.

They came twice a week for physiotherapy in classes lasting for about 40 minutes. They were of course told the importance and necessity of practising at home, but this is obviously not the same as having the encouragement and help of the physiotherapist.

They also insisted upon keeping this appointment whatever the weather, in spite of being asked not to attend in wet, cold or foggy days. The majority of the patients also had little or no heating in their bedrooms, so went from a stuffy living room to a cold bedroom which immediately started a "wheeze".

Today the picture is very different due to the decrease in T.B. in this country. Beds which were kept for patients with T.B. can now be used for the patient with chronic bronchitis and this has brought about a dramatic change both in treatment and in the well being of the patient.

The patient is usually admitted for a three weeks intensive course of treatment.

Lung function and sputum tests are done, antibiotics and steroids are given where necessary their effects watched carefully and their diet studied.

Instead of physiotherapy twice weekly it is given 3 or 4 times daily and it is very heartening to see how quickly the patients respond and improve.

Our aims of course are the same:

1. Relaxation--general and local.

2. Teaching of good diaphragmatic and lower costal breathing.

3. Modified postural drainage to help expectoration.
4. Teaching control of breathing whilst walking-on the level, on hills and stairs.

5. Gentle mobilisation exercises for trunk and thorax.

6. Teaching positions to help overcome breathlessness.

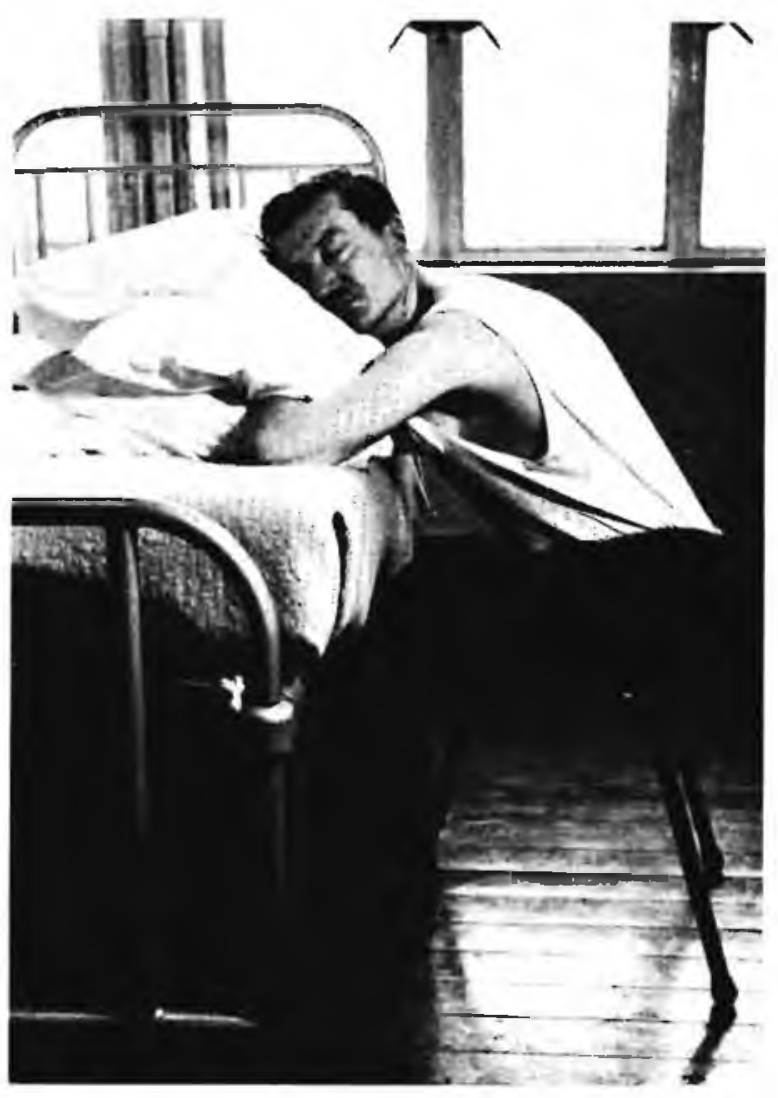

A position to help overcome breathlessness.

These patients need a great deal of very patient treatment; they are apprehensive and nervous and unwilling to do anything which may make them more breathless and start them wheezing.

The thought of any form of postural drainage frightens them; they have slept with five or six pillows or even in an armchair for long periods and are afraid to lie flat.

For this reason we have a modified form of postural drainage which we call postural coughing. The patient lies on one side with two pillows under his chest-his shoulders are on the bed and he needs two pillows under his head and his knees are bent.

In this position percussion and shakings are given and we find it most effective. We like to give ten minutes on each side, but at the beginning if the patient is very breathless he will only be able to tolerate five minutes on one side and will need to sit up and get into the high side lying position; then 


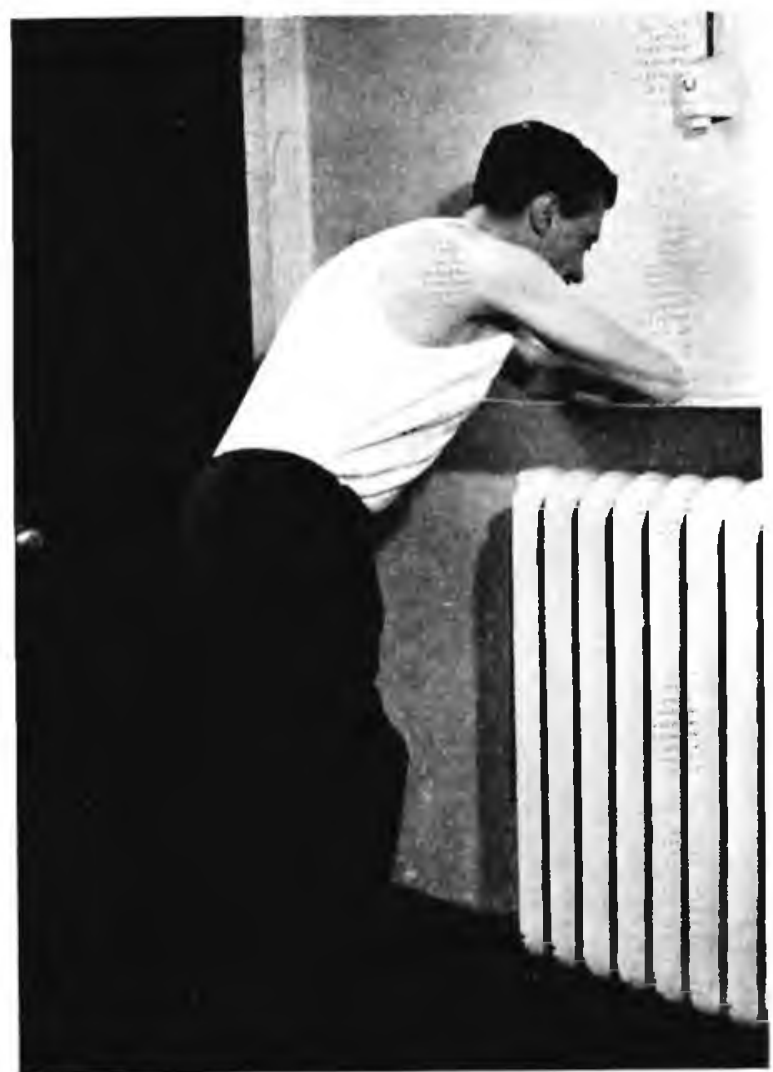

One of the positions to help overcome breathlessness.

after a rest will be able to do five minutes on the other side. This can be gradually progressed as he improves. Of course the patients should not be left whilst they are in the postural coughing position, and they will need to do it three or four times daily.

Every patient is given a sheet of exercises with diagrams showing all the positions to help them when they are breathless, and how to practise their breathing exercises together with two or three simple relaxing exercises. They practise all the different positions and discuss which position would help them the most in any given circumstance.

\section{THE BIRD RESPIRATOR}

The patient who is very breathless with sticky viscid sputum which is almost impossible to cough up is put on a course of treatment with the Bird Respirator.

The Bird is an Intermittent Positive Pressure Respirator which gives 40 per cent of oxygen and 60 per cent of air. At the onset of inspiration it delivers the mixture through a mouthpiece until a predetermined intrathoracic pressure is reached, usually $30 \mathrm{~mm} \mathrm{Hg}$, when the flow stops and passive expiration ensues. Isoprenaline is used in the nebulizer to act as a bronchodilator, 4 drops of 1 per cent solution in 46 drops of water and if the sputum is very viscid 2 drops of Axcosal is also added as this thins down the sputum.

If the patient is suffering badly from Anoxia and is only partially conscious a mask instead of a mouthpiece is used.

Providing the Bird is used correctly, it is invaluable but otherwise it is useless. The patient must just be taught how to breath using the bases of his lungs because it is here the sputum collects-thus he must be shown how to use the

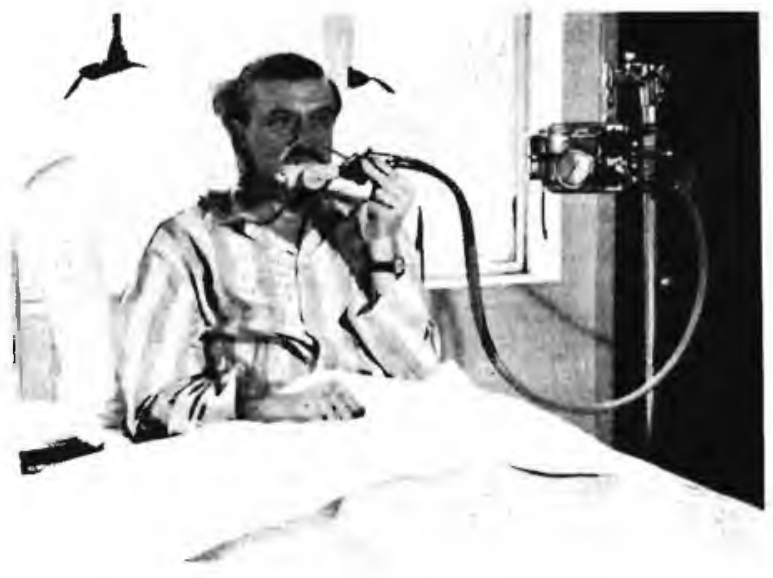

Bird Respirator in use with a mouthpiece.

machine. Some patients find this difficult and it may take several visits before they master the techniques.

The physiotherapist sets the machine at the appropriate setting for each patient according to the shape of his chest and the amount of resistance. She will encourage him to breathe with the bases of his lungs by placing her hands there and telling him to feel the air coming in at the lower part of his chest where he can feel her hands.

Once the patient understands he can continue the treatment alone, it should be given 3 times a day for twenty minutes. After about five minutes the patient will start coughing and the sputum will be expectorated quite easily.

It is very essential to prevent cross infection that each patient should not only keep his own mouthpiece but the whole of the tubing as well. This can all be sterilized when the treatment is finished.

For the patient who is only semi-conscious two physiotherapists will be needed; one to hold the mask in position and maintain the patient in a comfortable position, and the other to give vigorous percussion and shakings while the respirator is being used. We find a ten minute treatment given two hourly seems the most advantageous for these patients.

Every patient put on to a course with the Bird Respirator is taught by the physiotherapist and for this reason the respirators when used with the mask or mouthpiece are part of the equipment of the Physiotherapy Department.

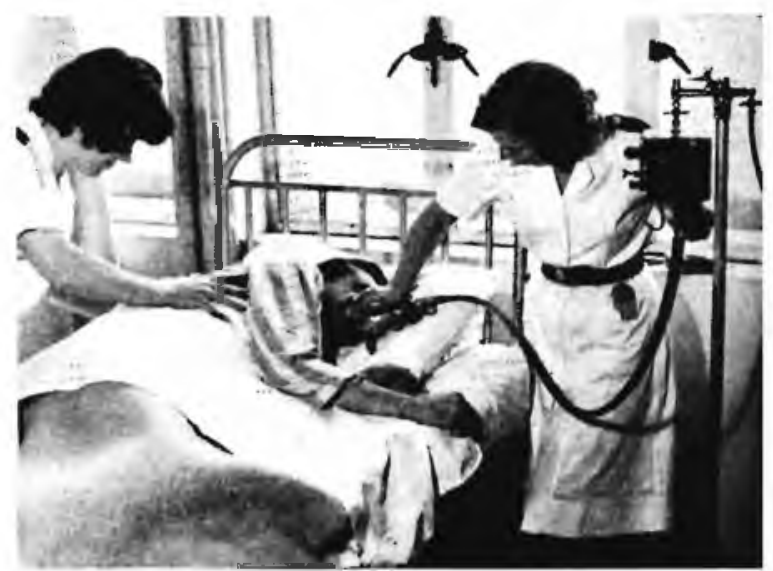

Bird Respirator being used with a mask 
It has also been found that if a respirator is not available, very good results can be obtained by using a humidifier with the same proportion of Isoprenaline and water with an oxygen cylinder. Again it is essential for the physiotherapist to be present and to give breathing instructions and shakings to the chest while the humidifier is being used. In this way the Isoprenaline will reach the bases of the lungs and the patient will be able to cough quite easily.

The Bird Respirator is also invaluable with the Paraplegic patient who has sputum and is unable to cough. It is very easy to feel in which area the sputum has collected, and the patient should be tipped in the appropriate position. He may use either the mask or mouthpiece; again shaking and percussion should be given and in a very few minutes he will start coughing. If firm pressure is then given on the abdominal wall he will get up the sputum without difficulty.

\section{Cystic Fibrosis}

A new and important field for physiotherapy has recently been opened with the treatment of babies and children with Cystic Fibrosis of the Pancreas or Fibrositic Lung Disease.

This is a disease of childhood which has become increasingly recognised since it was first described in 1938. Modern methods of investigation and treatment have been highly successful in prolonging the lives of these children who now have a good prospect of entering adolescence or adulthood.

The control of pulmonary infection is the key to survival. The successful management of this feature of the disease depends upon the combined efforts of the physicians, bacteriologist, physiotherapists and parents acting as a team.

Cystic fibrosis is an inborn disease which affects chiefly the lungs and digestive system. Until it was medically recognised 25 years ago these children usually died of pneumonia in the first year of life.

Later it was called mucovisidosis and the expectation of life was no more than five years.

Today cystic fibrosis is known to be the commonest genetically determined disorder affecting children in Britain. Most of the damage is caused by the excessive viscidity or stickiness of the mucus which is produced in the bronchii and also in the ducts of the pancreatic gland which provides enzymes to help digestion.

The major clinical problem is the lungs. There is great difficulty in keeping the air passages clear, especially when infection with bacteria or viruses greatly increases the amount of mucus. If the infection is not controlled areas of the lungs will be destroyed, and multiple lung cavities will develop.

Lntil quite recently doctors relied on anti-biotics alone to prevent lung infection and did not emphasise the necessity and importance of breathing and coughing exercises. Now while antibiotics remain an essential part of the treatment it is realised that physiotherapy too is absolutely essential.

\section{Symptoms}

Shortly after birth the symptoms may be slight; the child will have a cough which is not usual at an early age. The scools will be foul smelling due to the presence of large quantities of partially digested protein and they will also contain large amounts of unabsorbed fat and appear oily and greasy.

Usually the first symptom the mother notices is that the child tastes salty when kissed.

\section{Treatment}

1. Attention to nutrition.

2. Prevention and control of lung infection.

3. Respiratory education and other techniques for keeping clear the respiratory passages.

The treatment must be started as early as possible and therefore early diagnosis is essential.

The child may only be a few months old when admitted to hospital and will be barrier nursed to prevent infection.

The parents must realise that postural drainage and breathing exercises are essential for the child's survival and must be continued for its whole life.
As the child grows old enough to understand, the physiotherapy must be presented in such a way that it is accepted as part of the daily life and not something that makes him different from other children.

From the very early stages the mother will assist with the treatment in hospital so that she knows and completely understands how to continue when the child goes home.

With babies it is only possible to give postural drainage. They can be tipped and supported in the appropriate position over a cushion or the physiotherapist's knees, and gentle shakings and percussion given. The child will cough but most of the sputum will be swallowed. It may be necessary to use a fine catheter with a sucker to suck out as much as possible, either putting the catheter up the nostrils or over the back of the tongue.

When the children are between $2 \frac{1}{2}$ and 3 years old they will be able to start with breathing exercises, learning diaphragmatic and lower costal breathing, and now they will be able to do their postural drainage in their cots. It will probably be necessary to drain all areas of the lungs so a scheme must be worked out so that each area is drained, but the children do not become exhausted and begin to dread the postural drainage sessions. As they get a little older they will accept it as part of their daily toilet.

Later localised breathing exercises for all areas of the lungs will be given and postural exercises added. Some children may need a lobectomy and it is essential that they should be fit for this, with the rest of their lung fields clear and good localised movements.

These children are very rewarding to treat and it is a great joy to see them well and happy and leading a normal life at home and school, especially when one realises how bad their prognosis was only a few years ago.

Photographs by: Clifford Photography, Upper Harley Street, London, N.W.1.

All taken at Brompton Hospital, London.

\begin{tabular}{l}
\hline ORTHOPAEDIC MECHANICIANS \\
Manufacturers and Suppliers of: \\
ORTHOPAEDIC APPLIANCES, ARTIFICIAL \\
LIMBS, TRUSSES, SURGICAL CORSETS, \\
URINALS, ARCH SUPPORTS, COLOSTOMY \\
BELTS, ELASTIC STOCKINGS, ANKLE \\
GUARDS, WRIST GUARDS, ELBOW GUARDS, \\
KNEE GUARDS, LIGHT DURAL CRUTCHES \\
FOR CHILDREN, WOODEN CRUTCHES, AND \\
METAL ELBOW CRUTCHES. \\
Phone 23-2496 \\
312 Bree Street, JohannesbUrg \\
\hline
\end{tabular}

